\title{
MICROSCOPIC STRUCTURES AND SOME PROPERTIES OF SUPER WATER-ABSORBENTS OF HYDROXYETHYLCELLULOSE GRAFT COPOLYMERS
}

\author{
Namiko Miyata*1, and Isao Sakata ${ }^{* 2}$ \\ * Nakamura Gakuen College, Befu, Jonan-ku, Fukuoka, 814-01 Japan \\ ${ }^{* 2}$ Faculty of Agriculture, Kyushu University, Hakozaki, Higashi-ku, Fukuoka, 812 Japan
}

\begin{abstract}
The microscopic structures of the graft copolymers of hydroxyethylcellulose $(\mathrm{HEC})$ containing partially hydrolyzed polyacrylamide (P-Hyd-PAM) or poly(methyl acrylate) (P-Hyd-PMA) and poly(2dimethyl aminoethyl methacrylate) (PDM) synthesized as super water-absorbents and those of their geis were examined. The surfaces of HEC-P-Hyd-PAM, HEC-PDM and their gels were composed of granular and network structures, respectively, whereas those of HEC-P-Hyd-PMA and its gel were composed of a rod-like structure and an aggregate structure, respectively. The relation between their structures and some properties was examined.
\end{abstract}

\section{INTRODUCTION}

Super water-absorbents are now widely used in many fields, as sanitary materials, agricultural and gardening agents, and etc. The synthesis and some properties of super water-absorbents have been reported [1]. However, the microscopic study has not been reported except for grafted potato starch [2].

We have investigated the synthesis and properties of the super water-absorbents of graft copolymers based on hydroxyethylcellulose (HEC) and lignin $\{3,4]$. In this paper the differences in the microscopic structures of HEC and the dried HEC graft copolym. ers containing partially hydrolyzed polyacrylamide (P-Hyd-PAM), partially hydrolyzed poly(methyl acry. late) (P-Hyd-PMA) and poly(2-dimethylaminoethy! methacrylate) (PDM) as branch polymers and the hyd. rogels formed from them have been studied by optical (OM) and scanning electron (SEM) microscopes. The relation between their microscopic structures and some of the properties has also been studied.

The morphology of the fibrous cotton cellulose graft copolymers prepared in a heterogeneous state was examined by electron microscopy by Arthur et al. [5]. However, the morphology of the graft copo. lymers of water soluble cellulose derivative, HEC, which were synthesized in an aqueous solution name- ly in a homogeneous state, has not been reported.

\section{EXPERIMENTAL}

\subsection{Materials}

HEC with the molar degree of substitution of 1.2 was a reagent grade [3]. Super water-absorbents of HEC graft copolymers were synthesized as reported in a previous paper [3]. Table 1 shows the HEC graft copolymers used in this paper.

\subsection{Observation of Microscopic Structures}

The microscopic structures of the HEC, the HEC super water-absorbents and their hydrogels were observed by using JSM-T300 and JSM-5400 CRYO scanning electron microscopes with accelerating voltages of $15 \mathrm{kV}$ and $3.0 \mathrm{kV}$, respectively. The $\mathrm{HEC}$, the HEC super water-absorbents and their gels which were dyed with Methylene Blue or Acid Red were observed by an Olympus optical microscope.

\subsection{Absorbency and Viscoelasticity}

Measurement of absorbency of the HEC waterabsorbents was reported in the previous paper [3]. Viscoelasticity of their gels was determined by a Rheolograph-gel (Toyo Seiki $\mathrm{Co}_{\text {.) }}$ at $20^{\circ} \mathrm{C}$. Table 1 shows water absorbency, storage modulus ( $\left.E^{\prime}\right)$, loss modulus $\left(\mathrm{E}^{\prime \prime}\right)$ and loss tangent $\left(\tan \delta^{\prime}\right)$ of the HEC su. per water-absorbents. 
Table 1 Super Water-absorbents of HEC Graft Copolymers and Some Properties

\begin{tabular}{lcccccccc}
\hline Samples & $\begin{array}{c}\text { Crosslinking } \\
\text { agent } \\
(\%)\end{array}$ & $\begin{array}{c}\text { Degree of } \\
\text { grafting } \\
(\%)\end{array}$ & $\begin{array}{c}\text { Degree of } \\
\text { hydrolysis } \\
(\%)\end{array}$ & $\begin{array}{c}\text { Water } \\
\text { absorbency } \\
(\mathrm{g} / \mathrm{g})\end{array}$ & $\mathrm{E}^{\prime} / 10^{5} \mathrm{dyne} \cdot \mathrm{cm}^{-2}$ & $\mathrm{E}^{\prime \prime} / 10^{4} \mathrm{dyne} \cdot \mathrm{cm}^{-2}$ & $\tan \delta$ & Gel \\
\hline HEC-P-Hyd-PAM-1 & 0.3 & 331.0 & 65.4 & 1205 & - & - & - & - \\
HEC-P-Hyd-PAM-2 & 0.3 & 727.5 & 57.7 & 1551 & 1.8 & 3.0 & 0.17 & 7.8 \\
HEC-PDM-1 & 0.6 & 407.5 & - & 138 & 6.3 & 11.0 & 0.17 & 7.8 \\
HEC-PDM-2 & 1.0 & 11.6 & - & 562 & 2.5 & 7.1 & 0.28 & 7.7 \\
HEC-P-Hyd-PAM & none & - & 26.7 & 354 & 6.8 & 17.0 & 0.25 & 7.9 \\
\hline
\end{tabular}

a

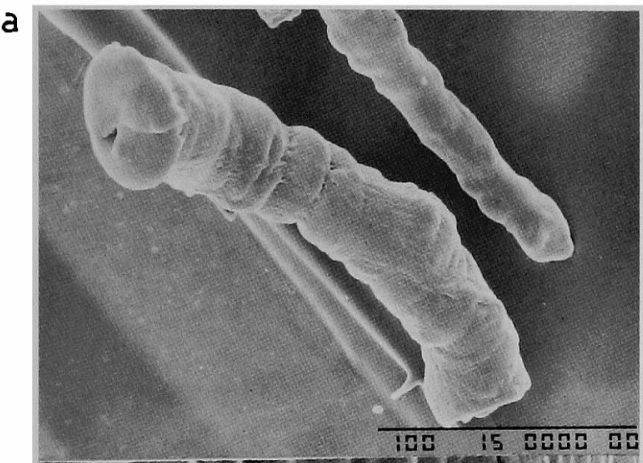

b

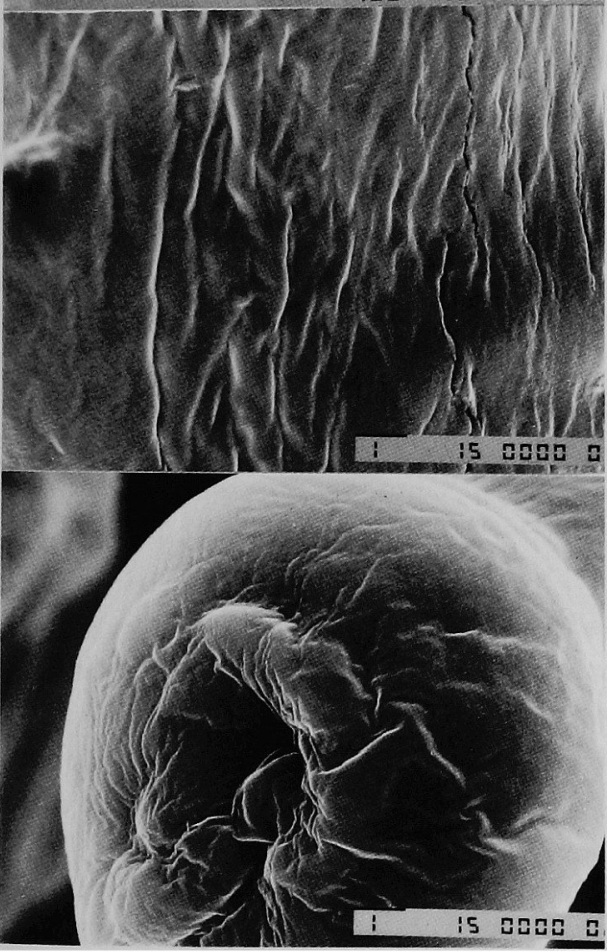

Fig. 1. SEM photographs of HEC: (a) whole view; (b) lateral view; (c) sectional view. Bars represent $100 \mu \mathrm{m}$ (a) and $1 \mu \mathrm{m}$ (b and c), respectively. a

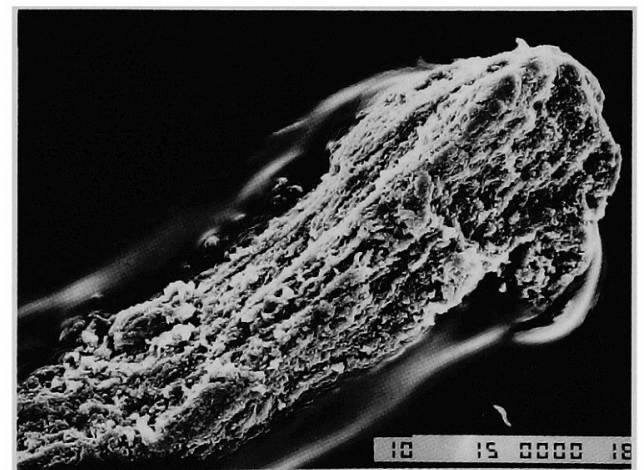

b

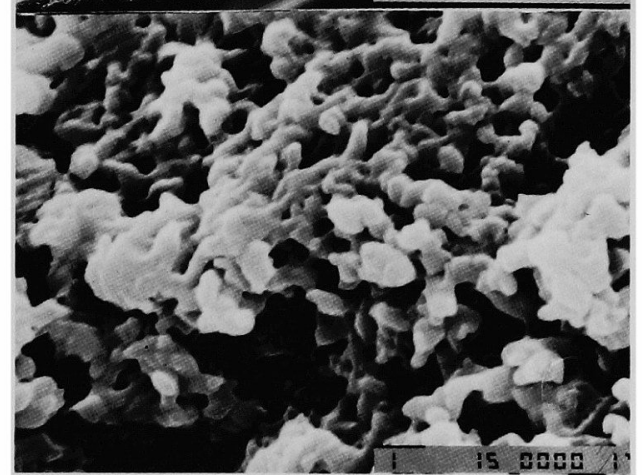

Fig. 2. SEM photographs of HEC-P-Hyd-PAM-1: (a) whole view; (b) lateral view. Bars represent $10 \mu \mathrm{m}$ (a) and $1 \mu \mathrm{m}$ (b), respectively.

\section{RESULTS AND DISCUSSION}

\subsection{Microscopic Structures of HEC and HEC Water-absorbents}

Figs. 1 and 2 show SEM photographs of HEC and HEC-P-Hyd-PAM, respectively, and Fig. 3 shows microphotographs of dyed samples of HEC, HEC-P-HydPAM-1, HEC-PDM-1 and HEC-P-Hyd-PMA. HEC used is in a fibrillar form and has relatively smooth surface as shown in Figs. 1 and 3(a), while HEC-P- 


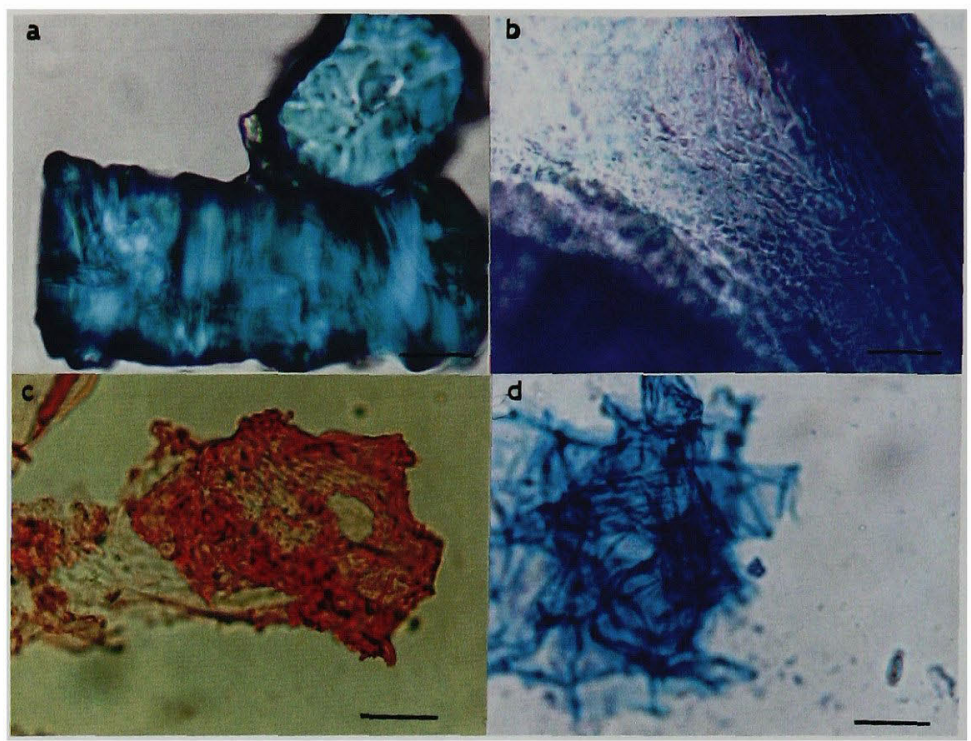

Fig. 3. Photomicrographs of dyed samples of HEC, HEC-P-Hyd-PAM-1, HEC-PDM-2 and HEC-P-Hyd-PMA: (a) HEC: (b) HEC-P-Hyd-PAM-1; (c) HEC-PDM-2; (d) HEC-P-Hyd-PMA. Bars represent $100 \mu \mathrm{m}$.

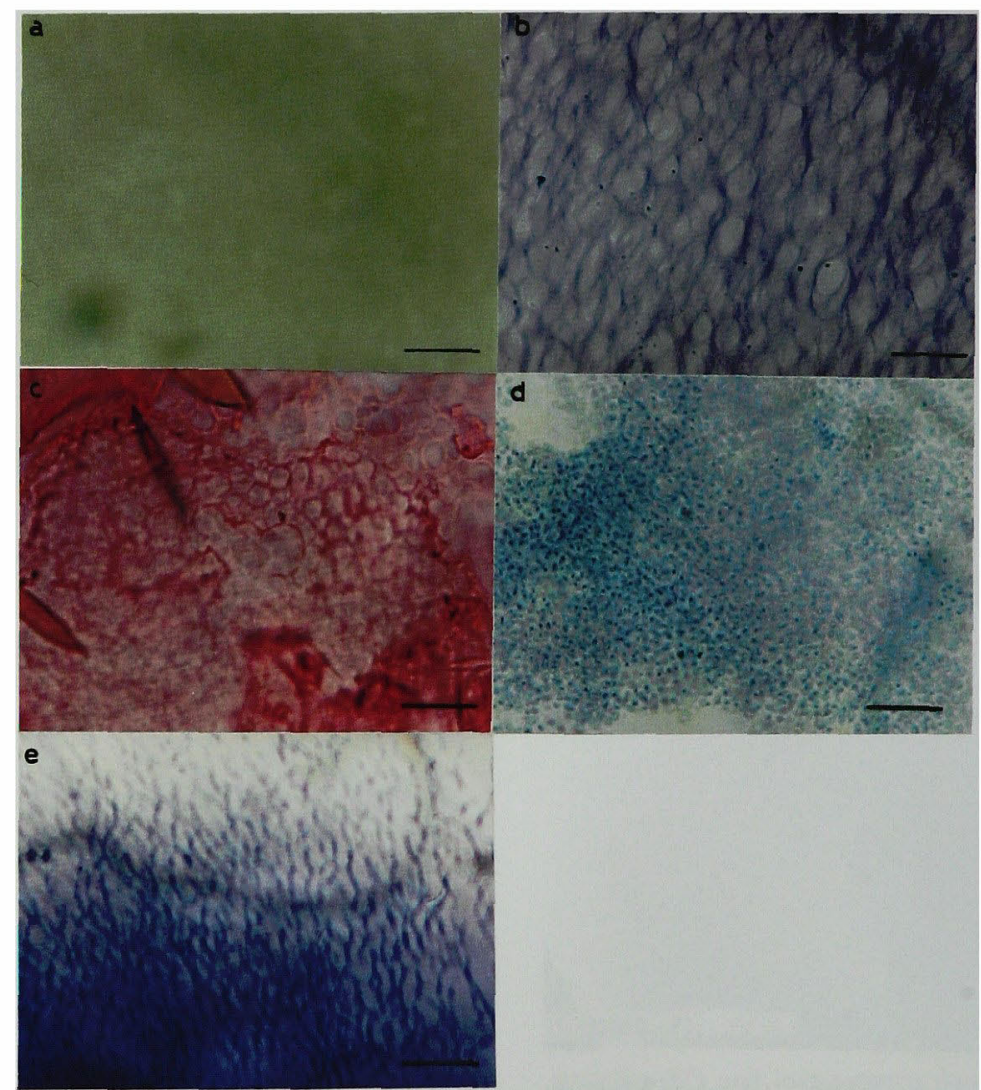

Fig. 6. Photomicrographs of $5 \%$ aqueous solutions of HEC (a), hydrogels of HEC-P-Hyd-PAM-2 (b), HEC-PDM-2 (c) and HEC-P-Hyd-PMA (d) and a swollen gel of HEC-P-Hyd-PAM-2 in $0.85 \% \mathrm{NaCl}$ solution (e): Absorbency: b, 521.0 $\mathrm{g} / \mathrm{g}$; c, $562.1 \mathrm{~g} / \mathrm{g} ; \mathrm{d}, 354.4 \mathrm{~g} / \mathrm{g}$; and e, $119.0 \mathrm{~g} / \mathrm{g}$. Bars represent $100 \mu \mathrm{m}$. 


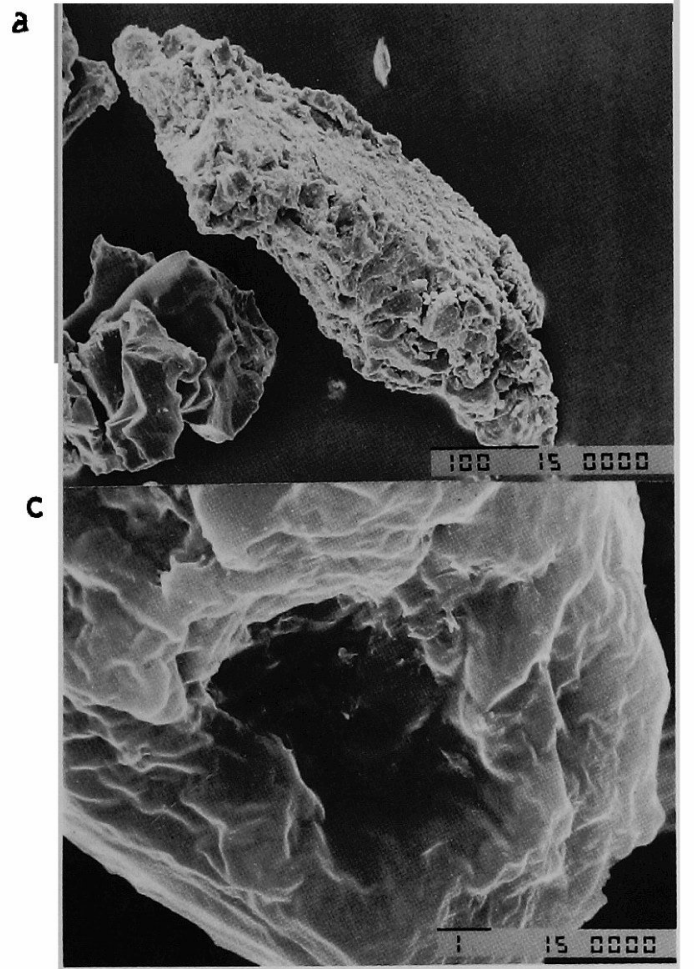

Fig. 4. SEM photographs of HEC-PDM-1: (a) whole view; represent $100 \mu \mathrm{m}$ (a) and $1 \mu \mathrm{m}$ (b, c and d), respectively.

Hyd-PAM-1 is composed of granules of about 200 $400 \mathrm{~nm}$ diameter (Fig. 2). Those granules form network and dendroid structures arising from more or less crosslinked PAM, judging from the observation by optical microscopy [Fig. 3(b)]. Thus, the shape and the appearance of the HEC were changed by grafting PAM onto HEC and the following hydrolysis of PAM. However, Gruber et al. [2] reported that the shape and the appearance of starch granules were not changed by grafting and that a thick layer of synthetic polymers was seen on the surface, but the core of the intact starch granule, i. e., the amylose core, was not grafted. This is supposed to be due to the low degree of grafting and the grafting method used in their work.

Figs. 3(c) and 4 show optical and SEM photographs of HEC-PDM. PDM was strongly grafted onto some of HEC. HEC-PDM-1 had smaller granules about $100-$ $200 \mathrm{~nm}$ width on the surface than the granules on the surface of HEC-P-Hyd-PAM-1 as shown in Figs. 2,

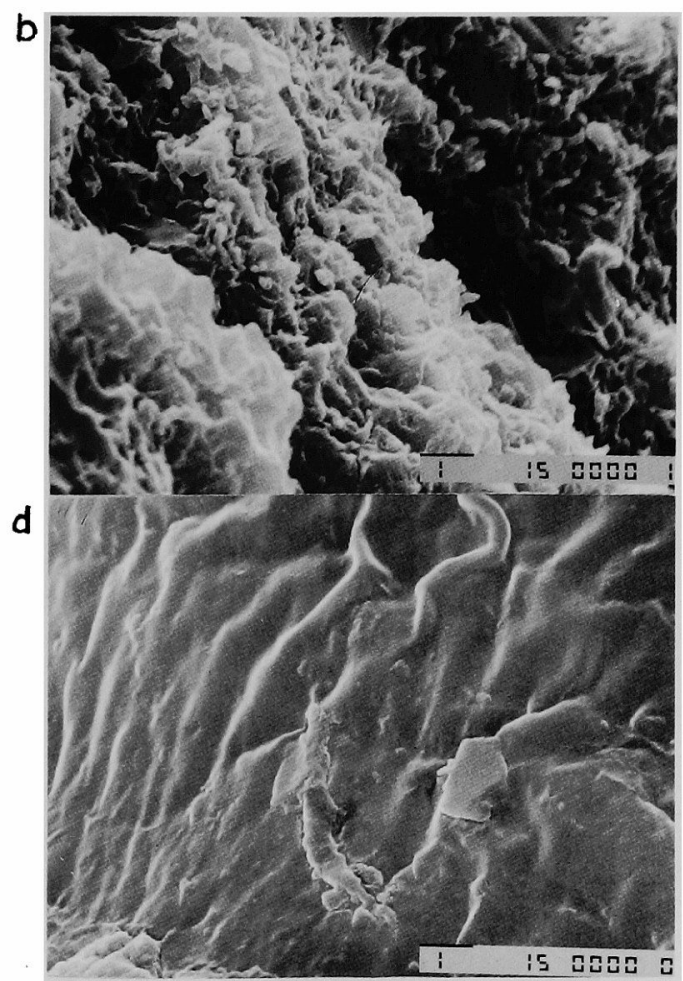

(b) lateral view; (c) sectional view; (d) lateral view. Bars 4 (a) and 4(b), whereas others were not so grafted as shown in Figs. 4(c) and 4(d). The ununiform grafting behavior as that of PDM was not observed in the cases of P-Hyd-PAM and P-Hyd-PMA. The smaller granular structure of HEC-PDM-1 is supposed to be due to the difference in the crosslink density: the amount of a crosslinking agent used was $0.6 \%$ for grafting of PDM onto HEC, while it was $0.3 \%$ in the case of HEC-P-Hyd-PAM-1. Fig. 3(c) shows that HEC-PDM-1 was mostly in a network structure though it was different from that of HEC-P-HydPAM-1.

Fig. 5 shows that HEC-P-Hyd-PMA was composed of rods of about $120-1000 \mathrm{~nm}$ width and 1000 $4000 \mathrm{~nm}$ long on its surface, and this rod-like structure was very different from the granular structures of HEC-P-Hyd-PAM-1 and HEC-PDM-1. Moreover, an optical microscopic photograph of the former was different from that of the latter as shown in Fig. 3. These different structure is supposed to be due to the 


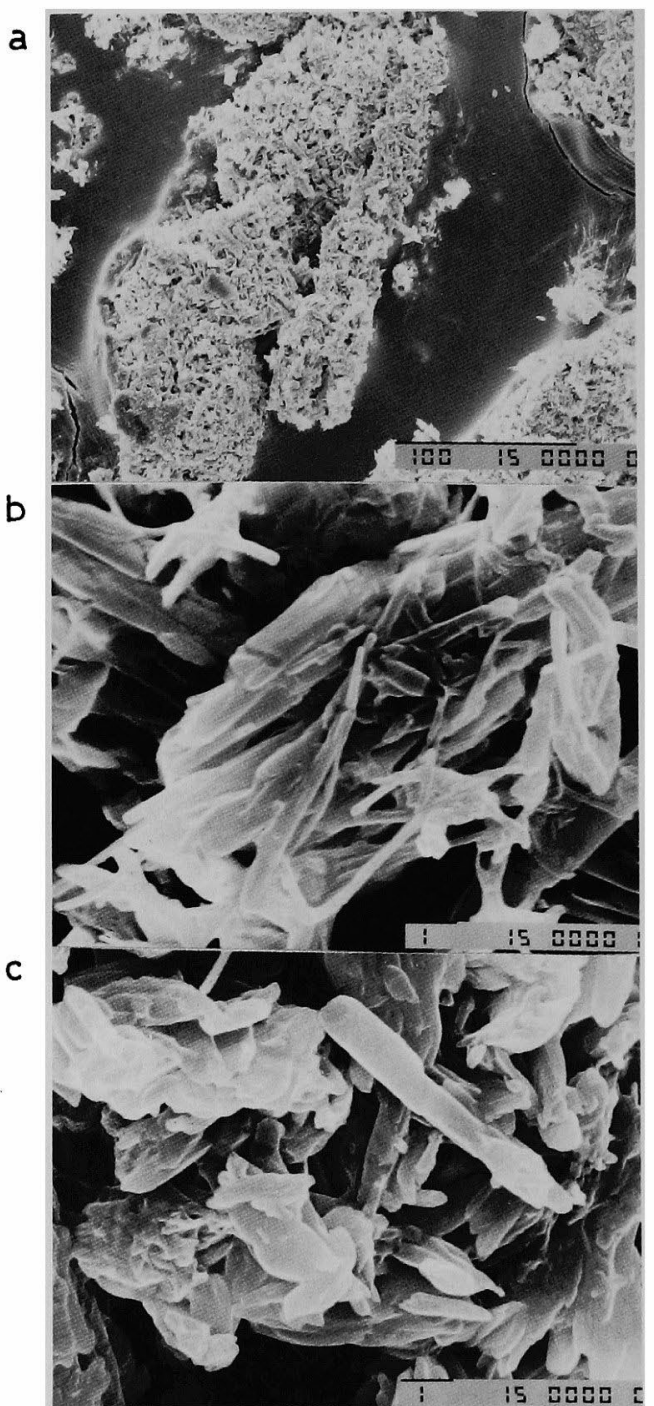

Fig. 5. SEM photographs of HEC-P-Hyd-PMA: (a) whole view; (b) lateral view; (c) sectional view. Bars represent $100 \mu \mathrm{m}$ (a) and $1 \mu \mathrm{m}$ (b and c), respectively.

effect of the amount of a crosslinking agent; in the case of HEC-P-Hyd-PMA no crosslinking agent was used, whereas in the cases of HEC-P-Hyd-PAM-1 and HEC-PDM-1 the amounts of crosslinking agent used were $0.3 \%$ and $0.6 \%$, respectively.

\subsection{Microscopic Structures of Gels of HEC Water- absorbents and Some Properties}

Fig. 6 shows microphotographs of $5 \%$ aqueous solution of HEC and the hydrogels of the HEC super water-absorbents dyed with Methylene Blue or Acid a

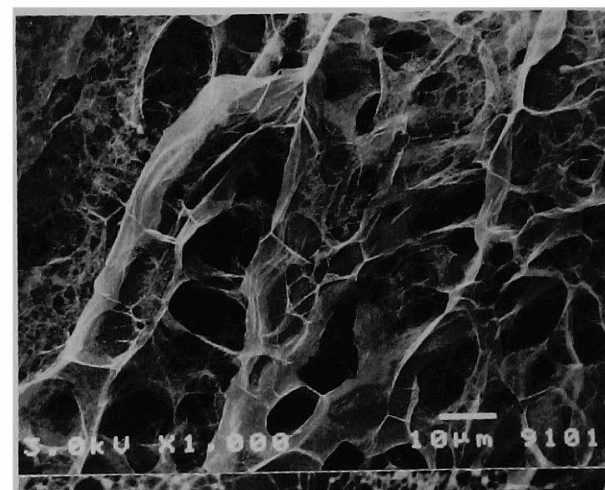

b

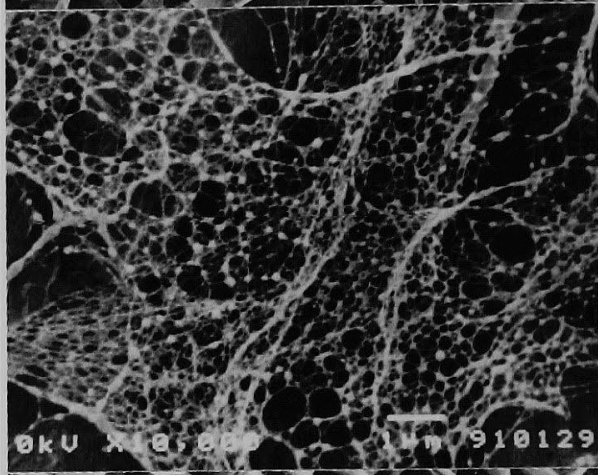

C

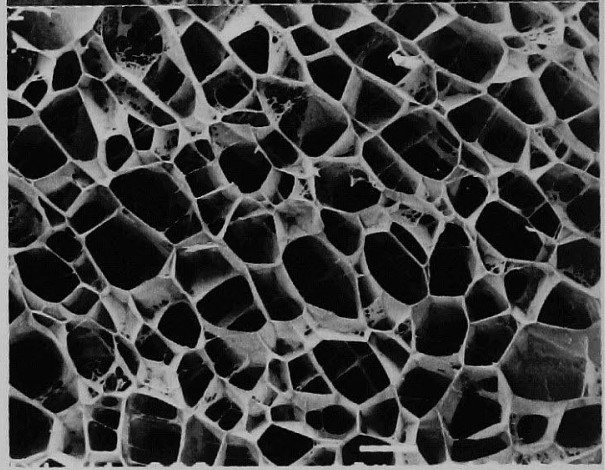

Fig. 7. SEM photographs of the gels of HEC-P-HydPAM-2 swollen in water and $0.85 \% \mathrm{NaCl}$ solution, respectively taken by CRYO SEM: (a) and (b) swollen gel in water; (c) swollen gel in $0.85 \% \mathrm{NaCl}$ solution. Absorbency: a and b, $1551.0 \mathrm{~g} / \mathrm{g}$; and c, $119.0 \mathrm{~g} / \mathrm{g}$. Bars represent $10 \mu \mathrm{m}(\mathrm{a}), 1 \mu \mathrm{m}$ (b) and $10 \mu \mathrm{m}$ (c), respectively.

Red. The microphotograph of $5 \%$ HEC aqueous solutions did not show any structure. It is interesting that the gels of HEC-P-Hyd-PAM-2 and HEC-PDM-2 show network structures arising from grafting in the presence of a crosslinking agent. On the other hand, the gel of HEC-P-Hyd-PMA forms no network but an aggregate structure, owing to grafting in the absence 
'of any crosslinking agent. The gel of HEC-P-HydPAM-2 forms looser networks than the gel of HECPDM-2 does as shown in Fig. 6. The former contains more water than the latter does and $E^{\prime}$ of the former was smaller than that of the latter as shown in Table 1.

Fig. 7 shows SEM photographs of the gels of HECP-Hyd-PAM-2 taken by CRYO SEM. The hydrogel of HEC-P-Hyd-PAM-2 in water shows a looser sponge structure than that swollen in $\mathrm{NaCl}$ solution.

$\mathrm{E}^{\prime}, \mathrm{E}^{\prime \prime}$ and $\tan \delta$ of the gels of HEC-P-Hyd-PAM-2 were the smallest among those of HEC water-absorbents in this paper, and therfore it is able to absorb a lot more water than other HEC water-absorbents. $E^{\prime \prime}$ and $\tan \delta$ of the gels of HEC-P-Hyd-PMA were the largest among the HEC water-absorbents as shown in Table 1. These results may be reflected to the structure of the gels; that is to say, the gels are not in network structure but in aggregate structure.

\section{REFERENCES}

1. G. E. Fanta, R. C. Burr, C. R. Russel, and C. E. Rist, J. Appl. Polym. Sci, 11, 457 (1967). Y. Masuda, "Super Water-absorbents", Kyouritsu Shuppan, Japan (1987)

2. Von E. Gruber, S. Alloush, K. John, and J. Schurz, Stärke, 24, 251 (1972) and 25. 325 (1973)

3. N. Miyata and I. Sakata, "Wood and Cellulosics", J. F. Kennedy, G. O. Phillips, D. J. Wedlock, and P. A. Williams Eds., Ellis Horwood, Chichester, U. K. p. 491 (1987); Sen ï Gakkaishi, 47, 95 (1991)

4. N. Miyata and I. Sakata, Sen'i Gakkaishi, 46, 356 (1990)

5. F. A. Blouin, A. M. Cannizzaro, J. C. Arthur, Jr., and M. L. Rollins, Text. Res. J., 38, 811 (1968). M. L. Rollins, A. M. Cannizzaro, F. A. Blouin, and J. C. Arthur, Jr., J. Appl. Polym. Sci, 12, 71 (1968) 